Proceeding Paper

\title{
New Quinoxaline-1,4-Dioxides Derived from Beirut Reaction of Benzofuroxane with Active Methylene Nitriles ${ }^{\dagger}$
}

\author{
Victor V. Dotsenko ${ }^{1,2,3, *}$, Karina V. Khalatyan ${ }^{1}$, Alena A. Russkih ${ }^{1}$ and Aminat M. Semenova ${ }^{1,4}$ \\ 1 Department of organic chemistry and technologies, Kuban State University, 149 Stavropolskaya Str, \\ 350040 Krasnodar, Russia; halatyan.karina@yandex.ru (K.V.K.); alena.russkih.19988@gmail.com (A.A.R.); \\ aminat-7@yandex.ru (A.M.S.) \\ 2 ChemEx Lab, Vladimir Dal' Lugansk National University, 20A/7 Molodezhny, 91034 Lugansk, Russia \\ 3 Department of Chemistry, North Caucasus Federal University, 1a Pushkin St., 355009 Stavropol, Russia \\ 4 North-Caucasus State Humanitarian Technological Academy, 36 Stavropolskaya St., \\ Cherkessk 369000, Russia \\ * Correspondence: victor_dotsenko@bigmir.net \\ + Presented at the 24th International Electronic Conference on Synthetic Organic Chemistry, \\ 15 November-15 December 2020; Available online: https://ecsoc-24.sciforum.net/.
}

Citation: Dotsenko, V.V.; Khalatyan, K.V.; Russkih, A.A.; Semenova, A.M.

New Quinoxaline-1,4-Dioxides

Derived from Beirut Reaction of

Benzofuroxane with Active

Methylene Nitriles. Chem. Proc.

2021, 3, 14. https://doi.org/10.3390/

ecsoc-24-08391

Academic Editors: Julio A. Seijas and

M. Pilar Vázquez-Tato

Published: 14 November 2020

Publisher's Note: MDPI stays neutral with regard to jurisdictional claims in published maps and institutional affiliations.

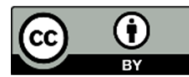

Copyright: (c) 2020 by the authors. Licensee MDPI, Basel, Switzerland. This article is an open access article distributed under the terms and conditions of the Creative Commons Attribution (CC BY) license (http://creativecommons.org/licenses /by/4.0/).

\begin{abstract}
Benzofuroxane reacts under Beirut reaction conditions with active methylene nitriles to give new 2-aminoquinoxaline-1,4-dioxides. The treatment of known 2-amino-3-cyanoquinoxaline1,4-dioxide with chloroacetyl chloride afforded corresponding chloroacetamide which is useful for the preparation of various heterocycles bearing a quinoxaline-1,4-dioxide core system.
\end{abstract}

Keywords: Beirut reaction; benzofuroxane; 2-aminoquinoxaline-1,4-dioxides; hetarylacetonitriles; malononitrile

\section{Introduction}

Quinoxaline-1,4-dioxides, mostly prepared through the Beirut reaction described for the first time by M. Haddadin and C. Issidorides at the American University of Beirut, Lebanon, in 1965, have been recognized as compounds of practical interest, primarily due to the wide spectrum of their biological activity (for reviews see [1-6]). Thus, 2-aminoquinoxaline-1,4-dioxides are known to possess leishmanicidal and antiplasmodial activities [7,8], anti-tumor activity [9], and antitubercular effects [10,11]. On the other hand, Tirapazamine (3-amino-1,2,4-benzotriazine-1,4-dioxide) (Figure 1), which has been known for a long time as an anticancer drug, has a very closely related structure. The above reasons prompted us to study the reactions of benzofuroxane with some active methylene nitriles in order to prepare new compounds with 2-aminoquinoxaline-1,4-dioxide core. Such compounds may be useful for the development of new antiprotozoal and anticancer agents.<smiles></smiles>

Figure 1. The structure of Tirapazamine (3-amino-1,2,4-benzotriazine-1,4-dioxide) closely related to 2-aminoquinoxaline-1,4-dioxides. 


\section{Results and Discussion}

First, we reacted benzofuroxane with 2-cyanomethylthiazoles [12], easily available by the Hantzsch reaction of cyanothioacetamide $[13,14]$ with phenacyl bromides (Scheme 1). Hybrid polyheterocycles 2 , bearing both thiazole and quinoxaline fragments, were recognized as the reaction products.<smiles>N#CCC(N)=S</smiles>

Scheme 1 . The synthetic pathway to 2-aminoquinoxaline-1,4-dioxides 2.

Then, cyanomethylpyrazole 3 , prepared by the reaction of malononitrile dimer with hydrazine $[15,16]$, reacted with benzofuroxane to give a product with the suggested structure 4 (Scheme 2). The evidence for the structure of compound 4 rests chiefly on its FT-IR spectrum, while its NMR data cannot be interpreted unambiguously. Thus, the IR spectrum revealed the presence of an amino group and conjugated $\mathrm{CN}$ group, while the band corresponding to the non-conjugated $\mathrm{CN}$ group was absent. This fact allows one to exclude the possible structure 5 (Scheme 2). The studies on the structure and reactions of compound 4 are in progress.<smiles>N#CCC(N)=C(C#N)C#N</smiles><smiles>CC(C)(C)C1CCCCC1(O)O</smiles><smiles>[O-][n+]1onc2ccccc21</smiles><smiles></smiles>

Scheme 2. The synthetic pathway to 2-aminoquinoxaline-1,4-dioxide 4.

Finally, we prepared 2-amino-3-cyanoquinoxaline-1,4-dioxide 6 by known method [17], which was reacted with chloroacetyl chloride. After short-term heating in $\mathrm{AcOH}$, a bright yellow precipitate of chloroacetamide 7 formed (Scheme 3). It should be noted that the only reported method for the chloroacetylation of 2-aminoquinoxaline-1,4-dioxides was based on the reaction of 6,7-difluoro-2-quinoxalinecarbonitrile 1,4-di-N-oxide with hardly available chloroacetic anhydride [11]. The compound 7 is expected to be a promising reagent for the synthesis of polyheterocyclic ensembles with quinoxaline core fragment. 
<smiles>N#CC1=C(N)N([O-])c2cc(F)c(F)cc2[N+]([O-])=C1C#N</smiles>

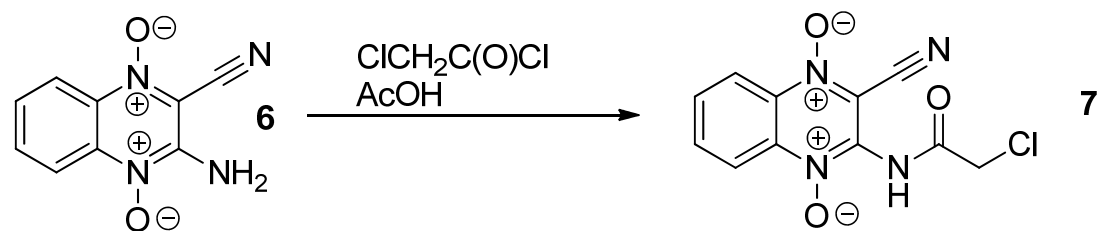

Scheme 3. Chloroacetylation of 2-amino-3-cyanoquinoxaline-1,4-dioxides.

\section{Experimental}

\subsection{Preparation of Compound 2: General Procedure}

Equimolar amounts of thiazol-2-ylacetonitrile 1 and benzofuroxane were dissolved in DMF and treated with the 1.5 eq. of base $\left(\mathrm{KOH}\right.$ or $\left.\mathrm{Et}_{3} \mathrm{~N}\right)$. The dark colored reaction mixture was left to stand in a freezer for $24-72 \mathrm{~h}$, then diluted with cold alcohol. The precipitated solid was filtered off and recrystallized to produce analytically pure samples of quinoxalines 2.

\section{Chloroacetylation of Compound 6}

2-Amino-3-cyanoquinoxaline 1,4-dioxide $6(0.01 \mathrm{~mol})$ was suspended in glacial $\mathrm{AcOH}(15 \mathrm{~mL})$ and treated with chloroacetyl chloride $(0.011 \mathrm{~mol})$. When the reaction mixture was gently heated to $50{ }^{\circ} \mathrm{C}$, the red color of 6 disappeared and the reaction mass turned bright yellow and then brick orange. The mixture was heated under vigorous stirring until the starting of 6 was fully consumed (TLC (thin-layer chromatography) control). The brick-orange precipitate was filtered off and washed with EtOH to produce pure chloroacetamide 7 at a yield of $90 \%$. The compound is soluble in hot DMF and DMSO, but sparingly soluble in $\mathrm{AcOH}, \mathrm{EtOH}$.

The representative spectra are given below (Figures 2-6):

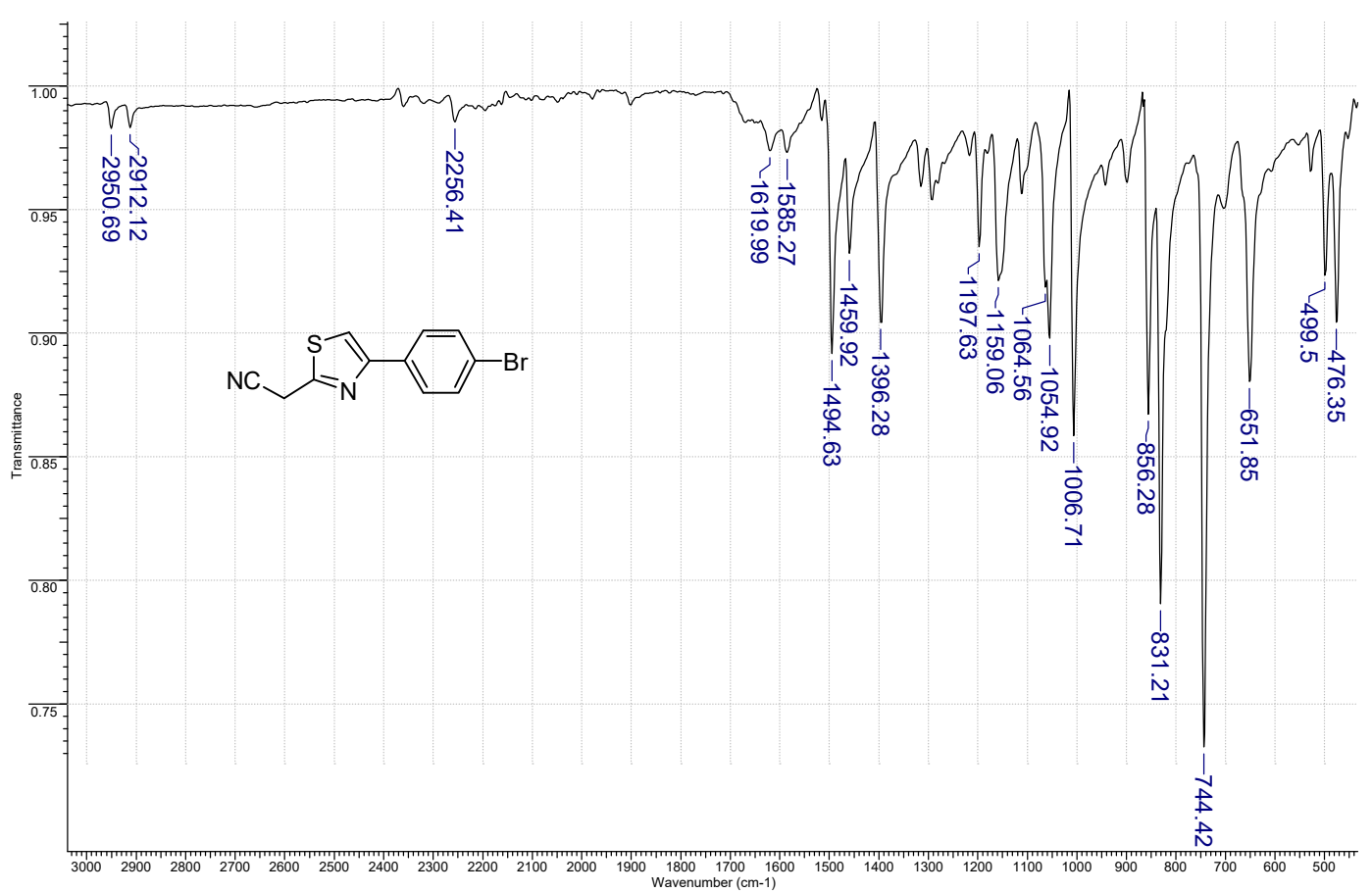

Figure 2. The FT-IR (ATR-Attenuated total reflectance mode) spectrum of 4-(4-bromophenyl)-2-cyanomethylthiazole 1a. 


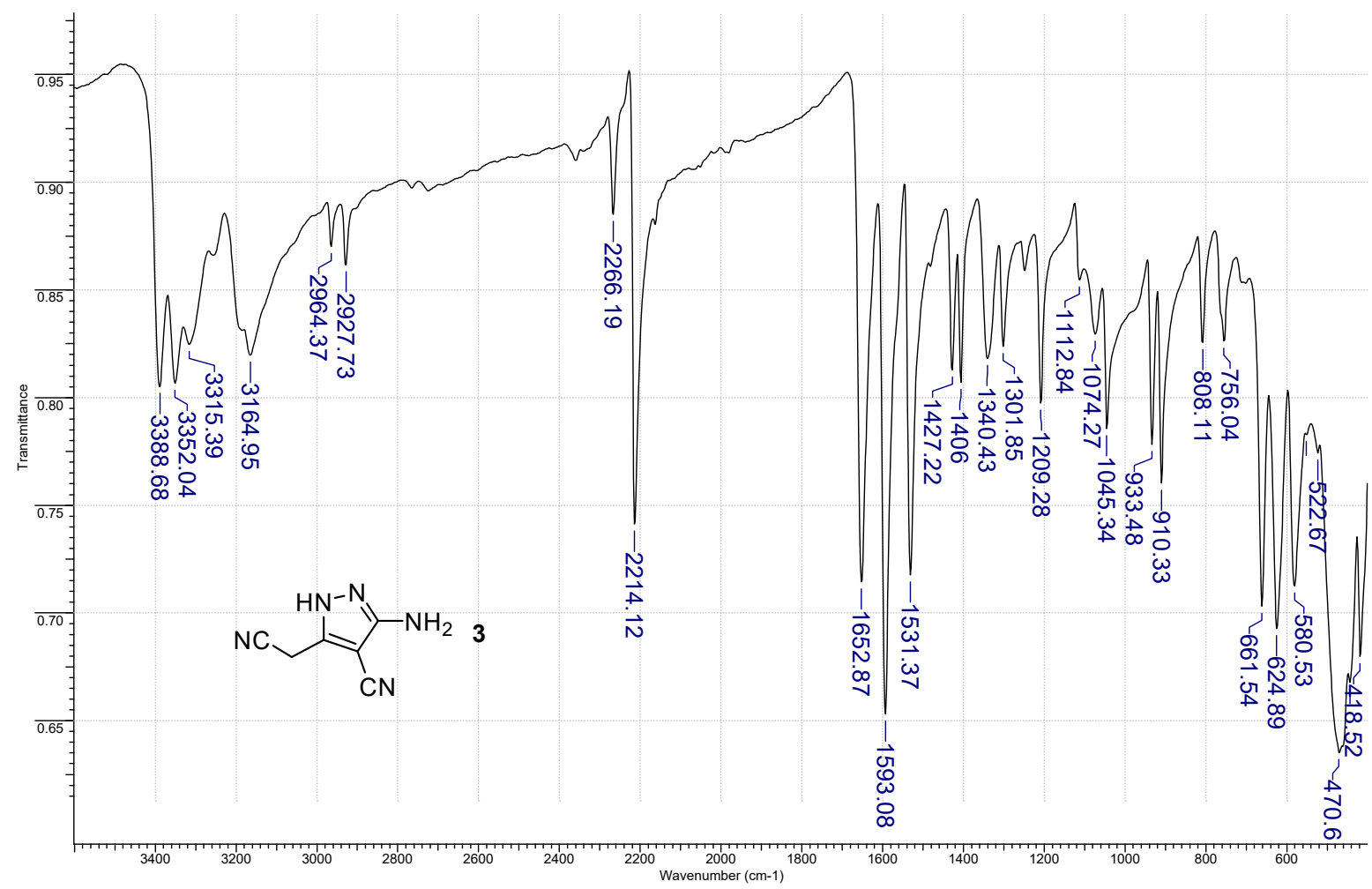

Figure 3. The FT-IR (ATR mode) spectrum of 3-amino-5-(cyanomethyl)-1H-pyrazole-4-carbonitrile 3.

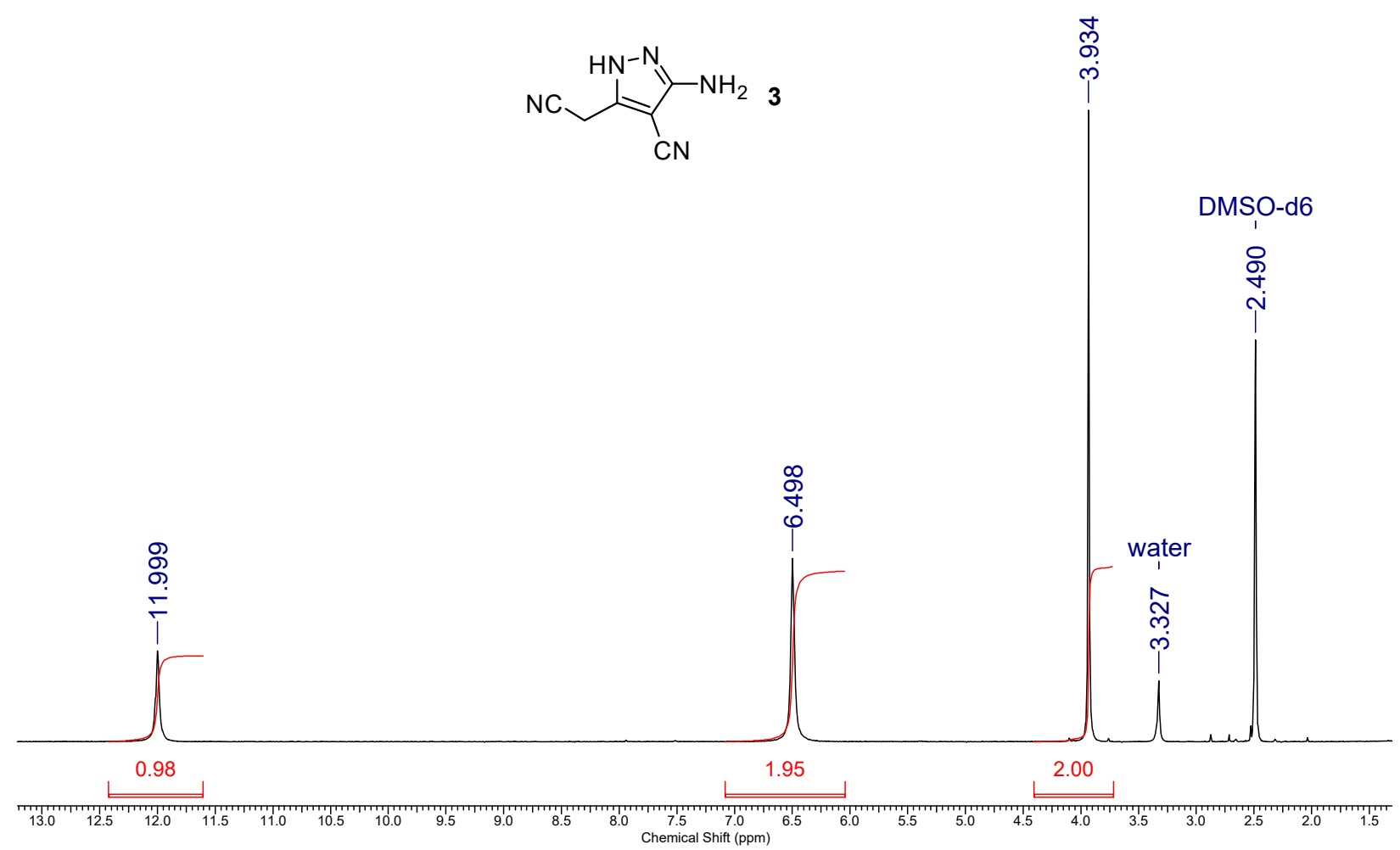

Figure 4. ${ }^{1} \mathrm{H}$ NMR spectrum (400 MHz, DMSO-d6) of 3-amino-5-(cyanomethyl)-1H-pyrazole-4-carbonitrile 3. 


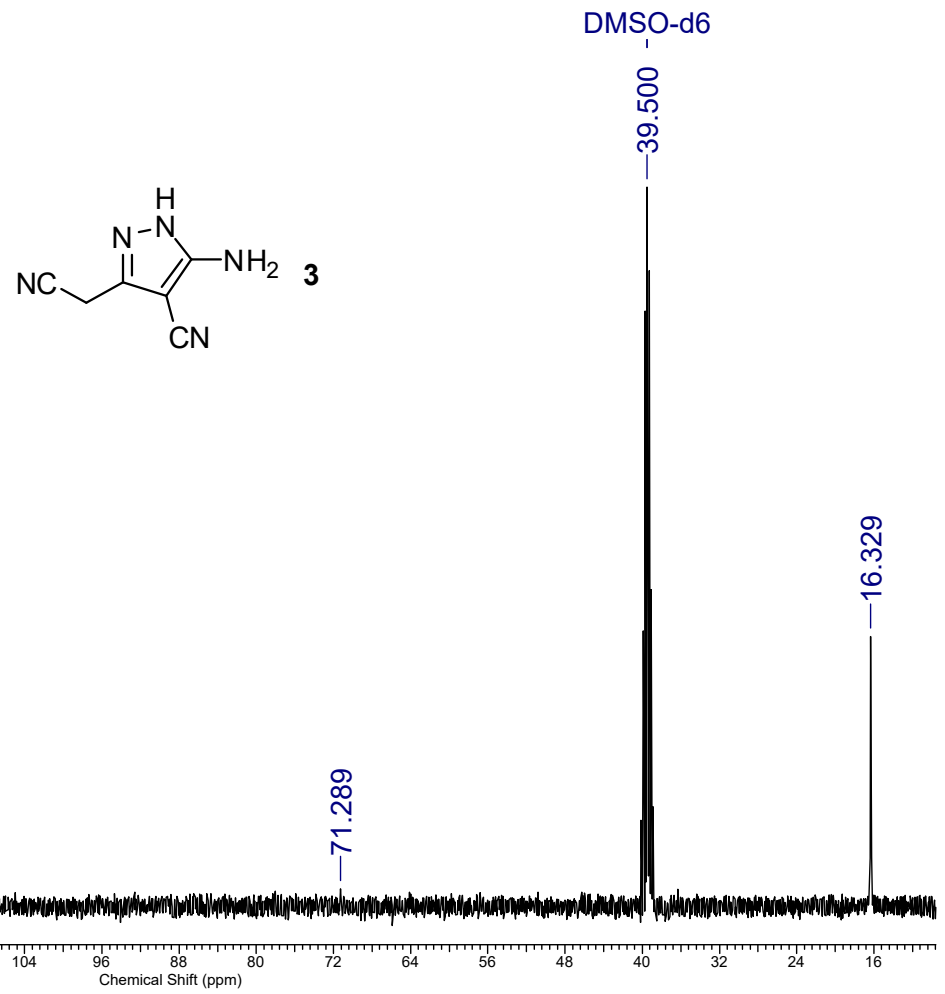

Figure 5. ${ }^{13} \mathrm{C}$ NMR spectrum (101 MHz, DMSO-d6) of 3-amino-5-(cyanomethyl)-1H-pyrazole-4-carbonitrile 3.

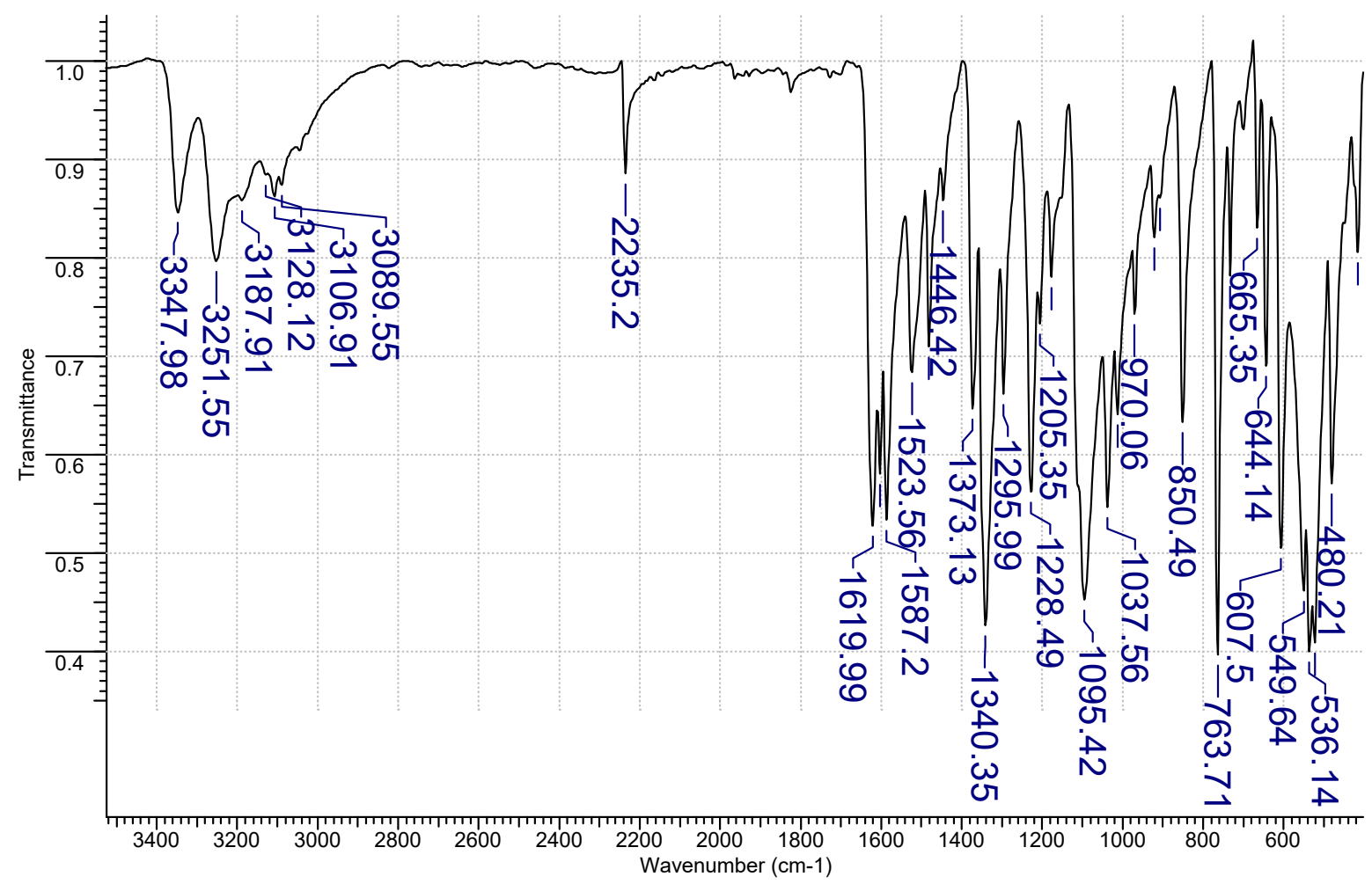

Figure 6. The FT-IR (ATR mode) spectrum of 2-amino-3-cyanoquinoxaline 1,4-dioxide 6.

Author Contributions: Conceptualization, V.V.D.; methodology, V.V.D.; formal analysis, K.V.K., A.A.R., A.M.S.; investigation, K.V.K., A.A.R., A.M.S.; writing-original draft preparation, V.V.D.; writing-review and editing, V.V.D.; supervision, V.V.D.; funding acquisition, V.V.D. All authors have read and agreed to the published version of the manuscript. 
Funding: This research was funded by RFBR and Krasnodar region according to the research project No. 19-43-230007.

Conflicts of Interest: The authors declare no conflict of interest.

\section{References}

1. Lima, L.M.; do Amaral, D.N. Beirut Reaction and its Application in the Synthesis of Quinoxaline-N, N'-Dioxides Bioactive Compounds. Rev. Virtual Quim. 2013, 5, 1075-1100.

2. Haddadin, M.J.; Issidorides, C.H. Application of benzofurazan oxide to the synthesis of heteroaromatic N-oxides. Heterocycles 1976, 4, 767-816.

3. Hamama, W.S.; Waly, S.M.; Said, S.B.; Zoorob, H.H. Highlights on the chemistry of 2-amino-3-cyano-quinoxaline 1,4-dioxides and their derivatives. Synth. Commun. 2020, 50, 1737-1757.

4. Mamedov, V.A.; Zhukova, N.A. Progress in quinoxaline synthesis (Part 2). In Progress in Heterocyclic Chemistry; Elsevier: Amsterdam, The Netherlands, 2013; Volume 25, pp. 1-45.

5. Mamedov, V.A. Synthesis of Quinoxalines. In Quinoxalines; Springer: Cham, Switzerland, 2016; pp. 5-133.

6. González, M.; Cerecetto, H.; Monge, A. Quinoxaline 1,4-dioxide and phenazine 5,10-dioxide. In Bioactive Heterocycles V; Chemistry and Biology; Springer: Berlin/Heidelberg, Germany, 2007; pp. 179-211.

7. Barea, C.; Pabón, A.; Pérez-Silanes, S.; Galiano, S.; Gonzalez, G.; Monge, A.; Deharo, E.; Aldana, I. New amide derivatives of quinoxaline 1,4-di-N-oxide with leishmanicidal and antiplasmodial activities. Molecules 2013, 18, 4718-4727.

8. Barea, C.; Pabón, A.; Castillo, D.; Zimic, M.; Quiliano, M.; Galiano, S.; Pérez-Silanes, S.; Monge, A.; Deharo, E.; Aldana, I. New salicylamide and sulfonamide derivatives of quinoxaline 1,4-di-N-oxide with antileishmanial and antimalarial activities. Bioorg. Med. Chem. Lett. 2011, 21, 4498-4502.

9. Monge, A.; Martinez-Crespo, F.J.; Lopez de Cerain, A.; Palop, J.A.; Narro, S.; Senador, V.; Marin, A.; Sainz, Y.; Gonzalez, M. Hypoxia-selective agents derived from 2-quinoxalinecarbonitrile 1,4-di-N-oxides. 2. J. Med. Chem. 1995, 38, $4488-4494$.

10. Ancizu, S.; Moreno, E.; Torres, E.; Burguete, A.; Pérez-Silanes, S.; Benítez, D.; Villar, R.; Solano, B.; Marín, A.; Aldana, I.; et al. Heterocyclic-2-carboxylic acid (3-cyano-1,4-di-N-oxidequinoxalin-2-yl)amide derivatives as hits for the development of neglected disease drugs. Molecules 2009, 14, 2256-2272.

11. Sainz, Y.; Montoya, M.E.; Martínez-Crespo, F.J.; Ortega, M.A.; de Cerain, A.L.; Monge, A. New quinoxaline 1,4-di-N-oxides for treatment of tuberculosis. Arzneimittelforschung 1999, 49, 55-59.

12. Schäfer, H.; Gewald, K. Zur Chemie des 4-Phenyl-thiazoly-(2)-acetonitrils. J. Prakt. Chem. 1974, 316, 684-692.

13. Dyachenko, V.D.; Dyachenko, I.V.; Nenajdenko, V.G. Cyanothioacetamide: A polyfunctional reagent with broad synthetic utility. Russ. Chem. Rev. 2018, 87, 1.

14. Litvinov, V.P. Cyanoacetamides and their thio-and selenocarbonyl analogues as promising reagents for fine organic synthesis. Russ. Chem. Rev. 1999, 68, 737-763.

15. Taylor, E.C.; Hartke, K.S. The Reaction of Malononitrile with Hydrazine. J. Am. Chem. Soc. 1959, 81, $2452-2455$.

16. Dotsenko, V.V.; Krivokolysko, S.G.; Semenova, A.M. Heterocyclization reactions using malononitrile dimer (2-aminopropene-1,1,3-tricarbonitrile). Chem. Heterocycl. Compd. 2018, 54, 989-1019.

17. Barea, C.; Pabón, A.; Galiano, S.; Pérez-Silanes, S.; Gonzalez, G.; Deyssard, C.; Monge, A.; Deharo, E.; Aldana, I. Antiplasmodial and leishmanicidal activities of 2-cyano-3-(4-phenylpiperazine-1-carboxamido) quinoxaline 1,4-dioxide derivatives. Molecules 2012, 17, 9451-9461. 